[the original paper has been published in: International Public Management Journal 3 (2000), 125 143, copyright with Elsevier Science Inc.]

\title{
QUALITY IN PUBLIC MANAGEMENT: THE CUSTOMER PERSPECTIVE
}

\author{
Kuno Schedler and Jürg Felix
}

\begin{abstract}
This article presents reflections on the transposition of the private-sector concept of Total Quality Management (TQM) to the public sector. We search for answers to the following questions:

- At what levels of the public sector is the concept of TQM operative?

- How must the concept of TQM be interpreted for its transposition to the public sector?

- What are the connections between the conventional quality-assurance control principles of public management and TQM?

TQM intends to exercise influence on organizational action. Action by the state and, in this specific case, by public management requires legitimization. For this reason, the notion of legitimization must be analyzed more closely, and the operative levels of TQM must be placed in their respective contexts. Legitimization may be considered to have three layers: basic legitimization is a product of the social contract and refers to the state and its structures in general terms; institutional legitimization relates to public management as an institution, and to its outward manifestations; and individual legitimization is the product of specific contacts between management and its customers. It is on this individual level that most changes are sought by New Public Management.
\end{abstract}

\section{Introduction}

The thesis of this study may be traced from the theme of a paper presented by Schedler at the International Public Management Network Conference in July 1996 titled, "Legitimization as Granted by the Client." (Schedler 1997) A comparison of the legitimization of state action in classic public administration literature versus under a results-oriented management perspective enabled a terminological differentiation to be made between the notion of the citizen that predominates in traditional government and administrative theory versus under New Public Management (NPM). Under NPM we assume the following:

a) "Citizens decide on the principle according to which the state is supposed to become active in a certain area, as well as on the extent and possibly the effects of such activities. This also includes management's obligation to achieve certain effects from the client's perspective;

b) clients, however, exert influence on the results of such activities (i.e. the concrete products)." In this respect they me be viewed as customers.

This differentiation of the notion of 'citizen' as customer resulted in a further differentiation, using the concept of legitimization. Whereas the political legitimization of administrative action comes from citizens, customers form the basis of the operative legitimization of public service provision. Citizens have a permanent existence; they usually assume their functions from birth. They can decline to be active in their capacity as citizens, yet they still retain their civic rights and duties. By contrast, custom- customers emerge by dint of individual and 
specific interactions with the state. Customers are only customers for as long as such an interaction lasts; afterwards, they lose their customer status but are free to enter into any new interaction at any time. During all this, they remain citizens, e.g., inhabitants of a city, a state or a country. Thus, when Mintzberg (Mintzberg 1997: 10) writes that he wants to be more than a mere customer, he wants to be a citizen, he misjudges these interconnections fundamentally: they do no involve an either/or, but a both/and relationship. Mintzberg does not lose his civic rights and duties when he asserts his operatively legitimized claims as a customer of public services. In his capacity as a citizen, however, he is able to partake in the decision regarding the claims to which he and all other citizens are entitled when they become customers of public services. It is precisely this circumstance that legitimizes him as a customer.

Schedler summarized his reflections on these definitions in the following proposition: (Schedler 1998: 37):

Customers complement citizens as the operative foundation of the legitimization of administrative action, but do not replace them. The notion of the customer reorients the operative autonomy of public management to a new reference group. Its autonomy of action is more clearly defined in the areas of performance and results.

This article attempts to advance the development of the concept of citizen as customer with the following objectives:

- to define the sources for legitimization of the state rather than to differentiate the notion of the citizen;

- to incorporate the notion of quality and its appropriate functions in the public sector;

- to delve deeper into the quality debate at a central point of operative legitimization, i.e. at the interface between business and government.

\section{Definitions of Legitimacy of Government and Governance}

State activities require legitimization from citizens; there is a wide consensus on this principle among academics and in political and practical working life. In legal terms, this relates to the principle of legality. The overriding objective pursued under the principle of legality aims to create a public sector and governance structures that are subject to constitutional control. (Gygi 1986: 75)

Given an increasing impact of business on the agenda of political and administrative systems that may be viewed to have risen to new heights since the early 1970s, related initially to protest against unnecessary and economically damaging government regulation, more and more observers in the private sector and among the citizenry generally are critical of today's basis of legitimization for government action and interaction in the economy and society. One perspective is that legality is no longer adequate as a legitimization for state action. The consequences that may be inferred from this view are manifold. They call for critical rethinking of much of the body of and principles of administrative law, and perhaps to the application of new criteria for the assessment of legality. (Bullinger 1991: 37) A second view avers that legality is of little use as a control principle, particularly in the area of performance management. Proposals from exponents of this view raise questions that call for a more differentiated application of the legality principle. Such proposals may be viewed to be based on the premise that the legality principle need not be applied with equal strictness throughout the public sector (Hablützel 1995: 502) 
Needless to say, constitutional and administrative lawyers prick up their ears when they hear such calls and warn of the threat of erosion of the principles of law. (Häfelin and Müller 1993: 69) A closer look at the propositions put forward by the critics of the legalistic view reveals, however, that their demands for reform do not aim at abolition of the constitutional and democractic functions of the legality principle. To the contrary: notions such as predictability, foreseeability and the avoidance of arbitrary action on the part of governments and public managers also may be found in the critics' vocabulary. A democratic functions argument provides a similar view: the complementary perspective should result in a reinforcement of citizens' democratic sensibilities. Thus, Schedler pointed out that with the introduction of new data-gathering and control instruments at the level of results, more balanced outcomes could be achieved than under traditional public administration frameworks. (Schedler 1998: 36)

In sum, it may be said that the critics' assertions call for complementary views of today's legality principle without jettisoning any fundamental principles of constitutional and administrative law, at least not without serious reflection. A more differentiated view of the respective positions requires that the legalistic approach be thought about in more relative terms. This is meant to provide the possibility to build bridges between opposing positions on the basis of state legitimization. For this purpose, the notion of legitimization is divided up into various aspects in this study. The following thoughts are based on what may be termed a new theory of layered legitimization. (Czybulka 1989: 67)

\section{Layered Legitimization}

In any democratic state, the legitimization of state action may be traced back to the sovereignty of the people, regardless of whether the democracy is representative or direct. Thus, the subject of legitimization is the citizen. Reflections on a layered form of legitimization would appear to be called for, however, if we discover that a citizen may be perfectly satisfied with the state as such but skeptical toward and dissatisfied with individual institutions of public management and the courts of law. This gap may even be more pronounced between a basically positive attitude toward the state and dissatisfaction with individual services provided by government. To reveal these differences is the goal of depicting a layered legitimization. In this article, overall legitimization is therefore divided up into three types: basic legitimization, institutional, and individual legitimization. The three layers of legitimization are then linked.

\section{- Basic legitimization}

Basic legitimization focuses on the fundamental consensus on which a state is based. It sets forth basic aspects which most often occur in situations of increased uncertainty. (Frey and Kirchgässner 1994: 10) The major characteristic of the concept of basic consensus consists of the rules that govern societal problems and structures and is not influenced by short-term and particular interests. Here, the subject of legitimization is represented by the citizens, who define the general conditions determining the basic consensus by exercising their democratic rights. The mode of legitimization differs in accordance with the basic democratic understanding prevalent in individual countries. Generally, however, it is represented in the election of politicians and members of the government by the people, and of other rights of the people, such as the right guaranteed under the Bill of Rights in the United States of America, or in the ability of Swiss citizens under constitutional provision to challenge government policy through public initiatives and national referendums that require popular vote on proposed or existing policies. 


\section{- Institutional legitimization}

If citizens make sweeping judgements of government policy and/or management, these are the expression of concern with institutional legitimization. Government and public management profits or suffers from its image, which also influences the appraisal of specific contacts, and vice versa. What is striking is that such judgements of state institutions cannot be brought into direct relation with issues of the basic consensus of a single individual's assessment of a single service provided by public management. Rather, questions about the 'right' organization or discernment of competencies that are center stage. The subject of legitimization under institutional legitimization is politics. Accordingly, the mode of legitimization is through the determination of the basis for predominating legal foundations.

\section{- Individual legitimization}

Whenever a citizen is involved in a direct transaction with a public institution, this is the layer of individual legitimization. Here, the citizen assumes an additional role, that of customer of public institutions and services. The differentiation between citizen and customer can be made on the basis of a comparison between generally abstract legal rules and individually specific legal acts. Whereas generally abstract legal rules are within the province of basic legitimization, individually specific laws belong to the layer of individual legitimization. The subject of legitimization of individual legitimization is thus the customer. The mode of legitimization is provided by the perception and consumption of public institutions and services. It is self-evident that in the area of individual consensus, the majority principle per se has little or no validity. (Czybulka 1989: 68) This, however, does not prevent us from advancing the concept of layered legitimization.

\section{- Relationships between the layers of legitimization}

The above definitions indicate that the individual layers of legitimization should not be viewed in isolation from the others. To the contrary, the individual layers of legitimization and their respective subjects of legitimization are engaged in a multifaceted interaction process. The following diagram provides a sketch of some of the interrelations between the different layers of legitimization and their subjects.

\section{Figure 1: The differentiation of civic roles and state legitimization}

\section{[Insert here]}

As shown in Figure 1, individual legitimization is based on a subjective perception of received services. (No difference is intended between law enforcement and services provided by administration). The yardsticks used by customers of public services include experiences from trade and industry. (Hablützel 1995: 501) The recognition of this fact is of fundamental importance since individual legitimization has an impact on both institutional and basic legitimization. The extent to which influences created by individual experiences reinforce or weaken the basic legitimization of the state may well depend on the explicit and/or implicit affirmation of individual legitimization, and vice versa.

In jurisprudence and, in particular, in debate concerning legal psychology, individual legitimization has long been recognized, at least implicitly. (Würtenberger 1996: 61) Similar reflections can be found in other fields, the number has increased conspicuously in recent 
years, that deal with public acceptance of administrative decisions. Würtenberger states that an administrative decision will gain acceptance if, "...it is not regarded as 'right' while still considered to be a (just) acceptable and (just) defensible arrangement, although in principle, one would have voted in favor of a different decision". (Würtenberger 1996: 62) This definition reveals differing statements of facts with regard to a customer-oriented understanding of quality in the public sector:

- Basic consensus is necessary: citizens exercise their democratic rights to establish fundamental quality standards (Shand and Arnberg 1996: 17) Shand and Arnberg refer to "higher-level values" that are intended to be valid within state institutions. This fact may strengthen the legitimization of administrative action, but it is not sufficient.

- Basic consensus is not sufficient: taking one's bearings from basic consensus is not sufficient for the acceptance of an administrative decision or the assessment of administrative performance. Here, additional quality standards come into play, such as the comprehensibility of the decisions, the interpretation of the principle of fair hearing, and the expenditure of time and money for services or actions demanded by citizens.

Thus far, we may not conclude definitively that public acceptance of government law or policy should be considered as the only prerequisite to establish or insure the legitimacy of state action. (Würtenberger 1996: 101) Against the backdrop of three-layered legitimization, however, individual acceptance should nonetheless be a decisive signpost to guide public officials' conduct. Management that is conscious of quality, and is correspondingly close to citizens, is able to make substantial contribution toward the achievement of this goal by consciously influencing any communication with specific customers or customer groups. (Rickenbacher 1995: 406) The following section therefore delves into the understanding of quality related to public sector service provision in more depth. Then, this interpretation of quality is integrated into the context of the theory of layered legitimization.

\section{Private Sector Definitions of Quality Applied to Public Management}

A review of usage shows that the understanding of quality has had a turbulent history even in private-sector organizations. (Seghezzi 1996: 16) The first generation of quality management operated a static form of quality assurance limited to compliance with technical standards. Only with increasing competition and thus with a shift from a sellers' to a buyers' market did it become evident that quality-conscious organizations had to take into account far more components. Subsequently, it was not the company with the most perfect solution that won the competition, but the company that was best able to satisfy customer requirements. The comprehensive quality management now prevalent in private industry did not, however, stop at introducing customer orientation as a new and conclusive aspect of Total Quality Management (TQM) to supplement technology and process control. Leadership and co-worker orientation, for instance, were recognized as success factors of sustained economic prosperity in the same measure as the societal responsibility that can be deduced from business activities. A transposition of TQM as rooted in the private sector into the public domain will therefore also entail a corresponding and comprehensive interpretation of quality, thus transcending far beyond "customer-oriented quality".

\section{A Comprehensive Understanding Of Quality In Public Management}

\section{- What is quality?}


Some indications of the philosophy of TQM are found in reference to the notion of quality as defined by the International Standardisation Organisation (ISO). According to this, quality is the entirety of characteristics and features of a product or service related to its suitability to satisfy fixed or expected requirements. (ISO 8402) It is characteristic of this definition that quality is assessed by the purchaser of a product. It would, however, constitute too short a perspective if customers were only considered to be end-users. This is indicated by the fact that the definition does not mention them explicitly. Comprehensive quality management does not only take into account external quality perception, but also internal quality perception.

External quality perception harks back to the individual legitimization discussed previously. Center ground is occupied by customers as recipients of state products, whose subjective perception judges whether the product provided by the state is capable of satisfying its purpose from a customer's point of view, too. Whether this is law enforcement, or other services provided by the state, is of secondary importance in the context of such fundamental deliberations. Our primary interest is in the above-mentioned acceptance of administrative products, and thus the way in which they are provided. Any detailed discussion can only be conducted on the basis of specific products. This is the case because acceptance and thus the assessment of quality by citizens is also partially determined by the nature of the relationship between public management and customer. For this reason, quality standards are always product-specific.

External quality perception can also be regarded as an "end-of-pipe" assessment of quality. This is not so with internal quality perception, that is based on the consideration that products provided to external customers can only be generated by the interaction of various components that have to be put into place in advance. Consequently, internal quality perception refers to the principle of internal supplier/customer relations. According to this principle, each producer of an internal service has to proceed according to the requirements of his internal purchaser, regardless of whether this service will ultimately be a contribution to an internal activity or be integrated in a product to be provided externally.

The point of departure consistent with the customer orientation that has thus been defined allows for the pursuit of further goals envisaged by TQM. Owing to the internal chain of customers, the responsibility for quality is no longer assumed by a central staff office, that promotes a job-specific quality consciousness. In addition, the network of internal supplier/customer relationships enables people to learn from their mistakes, and this learning process takes its bearings from the requirements of purchasers of products or their components. Experience in the private sector shows that the reduction of work inadvertently done twice over, the elimination of work that has no purchasers and the decrease in reworking time will result in substantial resources being saved. Moreover - and this might well have a primary benefit in the public sector - internal supplier/customer relationships will reinforce the internal coordination of management, which may ultimately lead to a reduction of externalized goal conflicts. The above indicates that the effects of TQM transposed to the public sector will primarily become evident at the levels of individual and institutional legitimization.

\section{The Functions of the State in the Context Of TQM}

The private-sector quality philosophy evolved from quality control into comprehensive quality management, as noted. In other words, quality is no longer merely controlled, but is managed. This inevitably points to the value of leadership. Leadership has become the piv- 
otal point of comprehensive quality management. This is also expressed in the Model Definition used by the European Foundation for Quality Management (EFQM):

The Model tells us that "customer satisfaction", "people (employee) satisfaction" and "impact on society" are achieved through "leadership" which drives the "policy and strategy", people management", "resources" and "processes", leading to excellence in "business results. (EFQM 1996: 13) This term is used in the private sector. Thus "policy" here denotes corporate policy, not government policy.

To assess where and how the public sector should assume its quality-oriented role of leadership, the understanding of leadership taken from the EFQM Model (EFQM 1996: 20) is abstracted and transposed to the public sector. The results of this process lead to a dichotomous understanding of functions.

\section{Model Function}

The model function can be divided into two components, one internal to management, the other external to management. With regard to the quality philosophy pursued by individual offices or departments, the internal model function of public management is only slightly different from that in the private sector. Basically, it concerns the question of leadership in public management according to the criteria of a comprehensive quality management. In many countries, efforts along these lines were already initiated some years ago. Reports of success show that the transposition of the relevant instruments has not been prevented by obstacles inherent in the system. Special mention must be made here of the use of quality circles, the systematic recording of sources of errors and their elimination, and the orientation toward internally defined guidelines and quality standards.

A far more critical review must be conducted with regard to the realization of the internal model function in terms of vertical and horizontal coordination. Present-day administrative products increasingly reveal a tendency whereby their production is becoming continuously more complex. Thus, the issue of an order requires a far more differentiated and multidimensional assessment of interests today than was the case only twenty years ago. The situation becomes even more complex if the order is, at the same time, preceded by a risk assessment involving a high degree of uncertainty. In these circumstances, it is obvious that public management runs the risk of externalizing goal conflicts and deferring decisions. Approaches of (negative) coordination are partially in place; however, the organizational measures to be inferred from them are not taken.

The quality-oriented external model function is receiving much less attention in public management at this juncture. However, public sector TQM requires an understanding of quality that far transcends the organizational limits of public management itself. The external model function can be divided up into a trans-organizational coordination function and a function which regards existing private-sector quality approaches as an integrative instrument.

Products and services provided by the state are, in part, also offered by other profit-making and, above all, non-profit organizations. Most often, these products and services are charitable in nature. Consequently, customers of such products and services frequently purchase these from both state and non-state organizations. If, for instance, we look at the social sector, then state products and services aim at the stabilization or elimination of the unfortunate conditions of those concerned. Now, if customers purchase these products and services outside public management, this may lead to an erosion of products and services provided by the state, which is tantamount to an extremely inefficient use of resources. Moreover, it may 
be assumed that the failure to reach set goals will result in more resources being used in other administrative areas. A government department that has nailed the letters TQM to its mast should therefore not only be conscious of the relevant networks but should also coordinate them across organizational borders, according to the wishes of customers.

A quality-oriented external model function also means that the quality systems existing and established in the private sector should not only be recognized and used, but also actively shaped and developed. Present-day certification systems that exist in industry and increasingly also in the service sector still constitute a big reservoir of unused potential for public management. If, for instance, we look at certification according to ISO 9000 and ISO 14000 systems, then today's debate is limited to answering the question as to the extent to which relevant certification systems should be introduced in public management. However, Total Quality Management for the state sector means much more. To date, certifiable quality systems have, at best, defined relations between suppliers, entrepreneurs and customers. As long as the public sector is not actively involved in the creation and development of quality systems, it will be unable to shed its role as an exogenous organization. An active use, however, would mean that private companies would also integrate public management, like their suppliers and customers, into their decision-making and operative processes in a structured manner. If this potential should be used, it must be added, however, that the accredited certification authorities must reach advance agreement about what a certificate actually expresses. (Malorny 1996: 56)

\section{Promoter Function}

The promoter function also can be divided into internal and external aspects. The internal promoter function represents the counterpart of the internal model function. The central position is occupied, on the one hand, by the promotion of improvement processes and thus the promotion of a quality-oriented organizational culture. On the other hand, the promoter function is supplemented by the concomitant recognition and appreciation of co-workers who behave in a quality-conscious manner. Here, too, experience shows, in a way similar to the internal model function, that the introduction of concepts along these lines meets with few obstacles inherent in the system. For this reason, it is not dealt with in any greater detail here.

With the external promoter function, the state expresses its acknowledgement and appreciation of the efforts and achievement of trade and industry in connection with the introduction and reinforcement of quality-oriented organizations. In some countries, this external promoter function is exercised through the award of national quality prizes, e.g., in Germany and the U.S.

Figure 2 provides a summary of the various functions performed by Total Quality Management in the public sector.

\section{Figure 2: Functions of TQM in the public sector [Insert here]}

\section{Quality Management In The Context Of Layered Legitimization}

In review of the functions of TQM in the public sector, it is conspicuous that the target area of quality management is limited to the institutional and individual layers of legitimization. No direct influence from basic legitimization can be perceived. It must be expected, how- 
ever, that TQM will have an indirect impact in the form of reinforcing effects upon basic legitimization.

At the same time - and under the same premise as the proposition of reinforcing effects - the integration of TQM into the three layers of legitimization highlights the fact that the values of basic legitimization will have to be made part of administrative action as special kinds of quality standards. They constitute the "generally abstract" quality standards that describe the desired level and type of social coherence within a state.

\section{Basic Attributes of Quality}

Depending on point of view, quality of public service is defined in very different ways. For many people, it is a "good form of government" that is central to the quality debate, while others focus on the predictability and thus on the constitutionality of state action. A more recent discussion emphasizes standards of conduct in the management against a similar background. Synnerström (1998, p. 1) highlights that:

"In most central and eastern European countries, however, aspirational efforts are not enough and the basic legal and institutional infrastructure needs to be strengthened. Further, the decentralization of the public management in these countries creates new opportunities for graft if appropriate control mechanisms are not put into place."

In the context of New Public Management, such questions are primarily depicted as restrictions on the applicability of NPM. This does not take into account that the new steering mechanisms also make a substantial contribution to state quality as experienced by citizens and thus to its acceptance among ordinary citizens. Countries in transition teach us that constitutionality and closeness to citizens are not mutually exclusive but represent complementary concepts. Verebélyi (1996: 23) describes four fundamental objectives of Hungarian administrative reforms, of which two concern the framework, the institutions and constitutionality, while the other two simultaneously aim at improvements in efficiency and quality, as well as "a smaller, simpler, faster and more cost-efficient public management."

Operative optimization creates a field of tension between stability (or predictability) and development capacity. The processes of direct democracy and the constitutional state aim strongly at the creation of a stability-oriented administrative organization. In this (bureaucratic) concept, it is incumbent on hierarchy and central coordination to integrate newly emerging challenges to the state into the existing organization. This means that the organization does not adapt to its environment; rather, systemic "disturbances" from the environment are channeled in such a way that they are unable to impose any lasting change on the system. In the face of this, however, there is an environment that is changing more strongly and faster, and according to New Public Management, these changes can only be countered by means of a dynamization of administrative organizations. Management should become changeable; the system should be able to respond to disturbances from the environment by means of adaptation.

To structure this wealth of demands made on the state and its management, we distinguish between basic factors and service factors. The basic factors are apt to strengthen societal consensus and the general acceptance of state institutions. A police force that does not collaborate with criminal syndicates; an management that makes decisions and grants permits without having to be bribed; subsidies that inure those who are in fact entitled to them; the use of taxpayers' money for public purposes; all these fit into the area of basic factors and is 
apt to maintain the acceptance of the state among citizens. This involves primarily both basic and institutional legitimization.

Service factors, however, concern quality as perceived by customers, i.e. the quality that is generated in direct and specific contacts with customers. This primarily involves individual consensus, which can be promoted by means of good service quality. Yet, the institutional consensus, too, is affected by the service factors in that, say, the image of the management as a whole will have an influence on the acceptance of its representatives and their performance among the recipients of products and services (and thus, indirectly, among politicians). Quality perception is thus also influenced by institutional potency.

Institutional consensus constitutes the interface between the basic factors and the service factors of quality, and it may be expected that this overlap will result in a lack of clarity when it comes to demarcation in empirical surveys. Customer surveys such as that conducted in St. Gallen, Switzerland (see below) refer primarily to service factors, while general surveys among the electorate tend to focus on basic factors.

\section{Figure 3: Basic Factors and Service Factors of Quality [Insert here]}

\section{Basic Factors In Practice: The 1998 UNIVOX Study}

Every other year, the GfS Research Institute in cooperation with Zurich University conducts a representative survey of 700 citizens eligible to vote in Switzerland. In 1998, this survey contained a question about the significance of various fundamental consensus principles of the state for the first time. The question concerned agreement with three different principles: constitutionality, economic efficiency, and promotion of coherence in Switzerland. According to the principle of the separation between basic and service factors, these state-governing principles are examples of basic factors.

\section{[Insert Table 1 here]}

Among what is interesting in these data is the fact that Swiss citizens express a high and broad level of agreement with all three principles, but champion the postulate of constitutionality with much less commitment than that of economic efficiency. It would, however, be wrong to conclude that the state's economic efficiency is generally regarded as more important than its constitutionality. Rather, this result must be interpreted as a sign of present necessities and deficits. At a time when industry suffers from partially revolutionary structural changes and increases in efficiency, the state is also expected to operate economically, and to perhaps change to become more efficient, perhaps adopting some NPM-oriented reforms. However, the Swiss population obviously does not perceive constitutionality to be a pressing problem. This serves to explain the lack of (emotional) commitment.

\section{Service Factors: The "Motivators" of the State}

In the 1970s, management theorists became concerned with substantive issues of motivation, among these Maslow and Herzberg. In this context, it became clear there are different categories of motivational factors that are interdependent and have varying effects on human behavior. Whereas Maslow (1973) emphasized the priority of certain requirements, Herzberg (1973) distinguished between so-called hygiene factors and motivators: 
- Hygiene factors are those whose existence or quantitative increase do not provide motivation. However, their absence or a quantitative lack of them will lead to dissatisfaction. They are thus "dissatisfiers".

- Motivators are factors whose absence or quantitative lack thereof tend to de-motivate. Their existence or quantitative increase will lead to greater satisfaction. They are thus "satisfiers".

Even though motivation theory has since homed in on different questions (e.g. process or assignment theories), theories of factors of motivation are still generally regarded as important and, according to Wunderer (1997: 146), are still taught and used both at universities and in practical working life. With reference to the questions addressed in this study - that also deal with motivational factors - it may be conjectured that there is a dependency between the various quality elements and management performance which resembles that between hygiene factors and motivators. The fundamental prerequisites of a modern democracy we have described as basic factors perhaps play the role of hygiene factors, while the perfecting elements described as service factors are comparable to motivators.

This nexus can be intuited if, say, we compare constitutionality with the management's friendliness toward customers. Constitutionality means that managers must always base its actions on applicable law. It therefore constitutes legitimization, a guarantee of citizens' equal treatment by, and their protection from, poor management. Its existence is a prerequisite of modern democracy, and infringements on it can be taken to court. The fact that this is the case does not lead to any particular satisfaction of citizens with the state, but its absence would create enormous dissatisfaction. Friendliness to customers means that management bases its actions on customer requirements and takes customers seriously, as business partners. A customer-friendly management in the public or private sector can substantially increase citizens' satisfaction whereas, according to the proposition, a bureaucratic management would be unlikely to create enormous dissatisfaction. This rough representation raises the question as to which quality factors must be assigned to which groups, and if such groups can be defined at all.

\section{Testable Propositions on Quality, Customers and Legitimacy}

The reflections noted above, supported by extensive interviews and with practitioners, permit a formulation of the following propositions for empirical assessment:

1. In assessment of the service quality of management, a distinction can be made between two groups of factors: basic factors, which are the prerequisite of state action, and service factors, which perfect the services.

2. As long as the basic factors are considered to be adequate, more attention is paid to the service factors and, on the surface, they are regarded as more important.

3. There is a relationship between the basic factors and the service factors that is comparable to that between Herzberg's hygiene factors and motivators.

4. Within the service factors, "soft" elements such as trust, partnership or well-being are experienced with more commitment than "hard" elements such as processing times or process costs.

One difficulty in testing these propositions results from the fact that the empirical material gathered in the St. Gallen survey reported below was not primarily recorded for these issues but, in the context of a secondary data analysis, was used for a similar, but not identical, purpose. Nonetheless, it is possible to postulate some relevant results at least with regard to tendencies. 


\section{Survey of St. Gallen Entrepreneurs}

In the winter of 1997, we conducted a study of administrative service quality in the region of St.Gallen; the survey was commissioned by the Canton and the City of St.Gallen. The object of the study was to search for the elements of service quality and their specific degree of success from the point of view of managers of companies of varying sizes. The survey was divided into three stages:

1. A qualitative preliminary survey by means of explorative individual interviews,

2. A quantitative survey by means of telephone interviews,

3. A qualitative follow-up survey by means of individual in-depth interviews.

For the purpose of this survey, a distinction was made between various quality dimensions, whose significance for corporate customers can then be questioned with the help of various items. To ascertain relevant quality dimensions, ten explorative interviews were conducted in the region of St. Gallen in the course of a preliminary survey.

\section{- Qualitative Preliminary Survey}

The qualitative preliminary survey aimed at finding the quality dimensions that would later be necessary for the quantitative telephone survey. Thus, the main subject was the question: "Which quality elements do you regard as important in your dealings with the management?" Eight entrepreneurs in the region of St. Gallen were interviewed in accordance with explorative guidelines; each interview lasted about 90 minutes. The results are summarized in Table 2. 


\section{[INSERT TABLE 2 HERE]}

\section{- Qualitative in-depth interviews}

To examine the results in depth, individual psychological explorations of about one hour in duration were conducted with nine managers, and then analyzed by IHA-GfM in qualitative-psychological terms. The selection was deliberate; it was based on the results of the quantitative survey: five were managers with very negative statements, and four were managers with very positive experiences.

Both with the very positive and the very negative elements, emotional aspects appeared to play a very important part. Positive weight is accorded to personal contacts ("they know me well", "like partners"). Negative experiences are primarily the consequence of an official's inner attitude. Such an attitude can, for instance, manifest itself where citizens have to adhere to very short deadlines while the management does not stick to any agreed dates. Most negative impressions registered in the CATIs refer to personal issues. They do not concern public office as a whole, or government performance, but the persons with whom customers come into contact. Thus, officials become the figureheads for their public office. Negative statements included:

- A defensive and uncooperative attitude;

- "You feel like a trouble-maker rather than a customer";

- Unfriendly and even arrogant style of communication (Interestingly, this impression was not confirmed by the quantitative study).

- Apart from emotional aspects, competence (very positive), and the aspect of time and an management's internal coordination (very negative) constituted a focal point of the qualitative statements.

The qualitative, in-depth interviews led us to conclude that customer orientation on the part of public managers and service providers is perceived to be a requirement, and is also appreciated in a positive sense. It manifests itself in:

- Respect for companies and persons;

- Treating citizens like customers;

- Active and competent consultation instead of (passive) officialdom;

- "Give instead of take" attitudes;

- Thinking and acting with a sense of partnership.

Finally, and of importance to the Canton and City of St.Gallen that commissioned the study, interviewees were asked to provide information about which criteria they regarded as most important for the assessment of a business location. The method used was a rational interview with projective questions. The following weighting was registered:

1. Partnership: "customer service", "providing a service ", "taking me seriously", "looking for solutions together", "putting no spokes in my wheels", "cooperation".

2. Personal contact: "establishing contact", "openness", "making me welcome".

3. Process: "uncomplicated", "competent", "transparent".

4. Time: "speed", "sticking to deadlines".

\section{Summary of Results and Conclusions}

Based on a review of relevant literature and analysis of the survey data reported here, the following results may be noted as preliminary findings relative to the propositions advanced above: 
Proposition 1: In assessment of the service quality of government, a distinction may be made between two groups of factors: basic factors, that are the prerequisite of state action, and service factors, that perfect the services.

Result 1: This distinction could not be supported empirically; the design of the St. Gallen survey served a different purpose and was primarily aimed at the service factors, not the basic factors. However, the results of the UNIVOX study serve to indicate that the requirements of constitutionality, economic efficiency and the promotion of coherence are sometimes understood as basic factors, while the service factors come into their own in specific contact situations between customers and public managers and service providers.

The qualitative interviews of St. Gallen managers, in particular, made it clear that the basic factors constitute the "support kit" for specific contact situations, thus implicitly influencing entrepreneurs' perception. Constitutionality, for instance, is regarded as given and forms part of the overall impression of government and public managers as contact partners, whereas the service factors characterize specific impressions from individual contacts.

Proposition 2: As long as the basic factors are considered by citizen customers to be adequate, more attention is paid to the service factors and, to a measurable extent, they are regarded as more important.

Result 2: Owing to the design of the study, this result also could not be supported empirically without ambiguity. However, the results of the individual interviews provided indications that confirm this proposition. Quite evidently, "matters of course" are not the object of profound reflection in the relational network between private enterprises and the state. The basic factors, which in Switzerland are regarded as largely satisfactory, will always only arouse entrepreneurs' attention if individual and specific problems occur. The rather densely woven constitutional network in Switzerland, however, largely prevents the perception of such problems as issues where law is at fault.

For the benefit of international comparative public management, the inference would have to be made that countries whose basic factors are not, or are not regarded as, sufficiently wellsecured, should not aim primarily at the perfection of service factors. Rather, they should pursue reform policies that are primarily concerned with the basic factors. There are various indications, particularly from East European countries, that the reform concepts along the lines of New Public Management can and should only be sensibly introduced once the basic factors have been sufficiently secured. Thus, pushing some NPM-oriented reforms will lead to dissatisfaction and, most likely, failure.

Proposition 3: There is a relationship between the basic factors and service factors that is comparable to that between Herzberg's hygiene factors and motivators.

Result 3: We did not succeed in either confirming or rejecting this proposition. Any indications to speak for or against the accuracy of this proposition were insufficient to argue either for or against the proposition. For this reason, the proposition will have to be addressed in a future research project and examined in depth. Our gut feeling is that the proposition is supportable.

Proposition 4: Within the service factors, "soft" elements including trust, partnership and feelings of well-being are related to higher public commitment than "hard" elements such as processing times or process costs. 
Result 4: This proposition was supported in analysis of both the quantitative and qualitative survey data. The correlation of individual factors of cooperation with the overall satisfaction with service quality was approximately $r>0.7$ throughout, which may be regarded as a significant correlation, while the majority of the remaining factors reveal less vital correlation.

In conclusion, it may be observed with some certainty that public perception of competence and a positive customer orientation appear to be related with a high degree of significance to overall satisfaction with the performance of government. This study reveals that service quality, as perceived by business entrepreneurs, is formulated in a mix of a wide variety of variables. The significance and weighting of these variables is likely to be situationally influenced to a considerable degree and changeable both within and across national, regional and local contexts. Finally, this research supports fully the notion that citizen satisfaction, or lack thereof, may be successfully researched and analyzed within a framework that views citizens as customers of public services.

* Kuno Schedler is Professor of Public Management at the University of St. Gallen, St. Gallen, Switzerland. Jurg Felix is a doctoral candidate in the Institute for Public Services and Tourism, University of St. Gallen, Switzerland. The authors wish to thank Lawrence R. Jones for his assistance in drafting this article. 


\section{References}

Bullinger, M. 1991. Beschleunigte Genehmigungsverfahren für Eilbedürftige Vorhaben. BadenBaden: Nomos

Czybulka, D. 1989. Die Legitimation der öffentlichen Verwaltung - unter Berücksichtigung ihrer Organisation sowie der Entstehungsgeschichte zum Grundgesetz. Heidelberg: Müller C. F.

EFQM 1996. "Selbstbewertung." Richtlinien für den öffentlichen Sektor. Berneck: Rheintaler Druckerei und Verlag

Frey, G. and Kirchgässner, F. 1994. Demokratische Wirtschaftspolitik. Theorie und Anwendung. 2nd ed., München: Vahlen

Gygi, N. 1986. Verwaltungsrecht, Eine Einführung. Bern: Stämpfli

Hablützel, P, 1995. „New Public Management als Modernisierungschance - Thesen zur Entbürokratisierungsdiskussion." in Hablützel et al., eds., Umbruch in Politik und Verwaltung. Ansichten und Erfahrungen zum New Public Management in der Schweiz, Bern, Stuttgart, Wien: Paul Haupt: 499 - 507.

Häfelin, U. and Müller, G. 1993. Grundriss des Allgemeinen Verwaltungsrechts. 2nd ed., Zürich: Schulthess

Herzberg, F et al. 1967. The Motivation to Work, 2nd ed., New York, London, Sydney: John Wiley

Maslow, A. 1973. Psychologie des Seins. München: Kindler

Malorny, C. 1996. TQM umsetzen, der Weg zur Business Excellence. Stuttgart: Schäffer-Poeschel

Mintzberg, H. 1996. “Den Staat besser managen - nur wie?” Harvard Business Manager 4: 9 -18 .

Schedler, K. 1997. "Legitimization as granted by the client: Reflections on the compatability of New Public Management and Direct Democracy." In L. Jones and K. Schedler, eds., Advances in International Comparative Management. Supplement 3 Greenwich, CT: JAI Press: 145 -168 .

Schedler, K. 1998. “Die Systemanforderungen des NPM an Staat und Recht." in P. Mastronardi and K. Schedler, eds., New Public Management in Staat und Recht. Bern, Stuttgart, Wien: Paul Haupt: 1 - 46

Rickenbacher, I. 1995. „New Public Management aus Sicht der Politik.“ in Hablützel et al. ,Hrsg., Umbruch in Politik und Verwaltung. Ansichten und Erfahrungen zum New Public Management in der Schweiz. Bern, Stuttgart, Wien: Publisher?:401 - 410. 
Seghezzi, H-D. 1996. Integriertes Qualitätsmanagement. Das St. Galler Konzept. München, Wien: Carl Hansen

Shand, D. and Arnberg, M. 1996. "Background paper." In , Responsive Government. Service Quality Initiatives. Paris: OECD.

Synnerström, S. 1998. "Promoting High Standards of Conduct in the Administration." In Public Management Forum. IV: 1 and 11.

Wunderer, R. 1997. Führung und Zusammenarbeit. Beiträge zu einer unternehmerischen Führungslehre. 2nd ed., Stuttgart: Schäffer-Poeschel

Würtenberger, T. 1996. Die Akzeptanz von Verwaltungsentscheidungen. Baden-Baden: Nomos 